\title{
Respostas do capim-Tifton 85 à aplicação de nitrogênio: cobertura do solo, índice de área foliar e interceptação da radiação solar
}

\author{
[Responses of the grass Tifton 85 to the application of nitrogen: soil cover, leaf area index, and \\ solar radiation interception] \\ A.P.P. Oliveira ${ }^{1}$, R.O.P. Rossiello ${ }^{2 *}$, L. Galzerano ${ }^{1}$, J.B.G. Costa Júnior ${ }^{3}$, \\ R.P. Silva ${ }^{3}$, M.J.F. Morenz ${ }^{2}$ \\ ${ }^{1}$ Aluno de pós-graduação - IZ-UFRRJ - Seropédica, RJ \\ ${ }^{2}$ Universidade Federal Rural do Rio de Janeiro \\ Rod. BR 465, $\mathrm{km} 7$ \\ 23890-000 - Seropédica, RJ \\ ${ }^{3}$ Aluno de graduação - UFRRJ - Seropédica, RJ
}

\section{RESUMO}

Estudaram-se os efeitos da adubação nitrogenada sobre o crescimento do capim Tifton 85 (Cynodon spp. cv. Tifton 85), em termos de ocorrência de plantas e altura do dossel, índice de área foliar e interceptação de radiação fotossinteticamente ativa. $\mathrm{O}$ estudo foi desenvolvido sobre um planossolo de ocorrência em campo experimental. Os tratamentos consistiram de níveis de $\mathrm{N}(0 ; 150 ; 300 ; 450$ e $600 \mathrm{~kg} / \mathrm{ha}$ de $\mathrm{N}$-ureia, aplicados em duas vezes), arranjados em um desenho experimental de blocos inteiramente ao acaso, com quatro repetições. As avaliações foram realizadas semanalmente, entre 10 e 40 dias após o corte. Tanto a ocorrência de plantas como a altura do dossel responderam à adubação nitrogenada, conforme um padrão de resposta que variou, sazonalmente, em função das doses de $\mathrm{N}$ em interação com as condições ambientais. A expansão da área foliar e a interceptação da radiação fotossinteticamente ativa associada, também foram controladas direta e proporcionalmente pelas doses de $\mathrm{N}$ aplicadas, sendo maximizadas a valores de índice de área foliar em torno de 4,0.

Palavras-chave: Cynodon spp., altura de dossel, frequência de plantas, radiação fotossinteticamente ativa

\begin{abstract}
The effects of nitrogen $(N)$ fertilization levels on the growth patterns of the grass Tifton 85 (Cynodon spp. cv.Tifton 85) were studied in terms of occurrence of plants, sward height, leaf area index, and photosynthetically active radiation interception $\left(P A R_{\text {int }}\right)$. The field trial was made in an experimental area. Treatments consisted of $\mathrm{N}$ levels $(0 ; 150 ; 300 ; 450$; and $600 \mathrm{~kg} / \mathrm{ha} \mathrm{N}$-urea, split in two applications) arranged in an experimental design of entirely randomized blocks with four repetitions. Plots were weekly sampled, from the day $10^{\text {th }}$ to $40^{\text {th }}$ after cutting. Both occurrence of plants as well as sward height were responsive to nitrogen fertilization according to a response pattern that seasonally varied, depending on $N$ rates and environmental conditions; thus, demonstrating their sensitivity as indicators of growth conditions and canopy structure. Leaf expansion and its associated PAR interception were also directly and proportionately controlled by $N$ rates, being maximized to values of leaf area index around 4.0.
\end{abstract}

Keywords: Tifton 85, Cynodon spp., sward height, frequency of plants, photosynthetically active radiation

Recebido em 19 de novembro de 2009

Aceito em 31 de março de 2010

*Autor para correspondência (corresponding author)

E-mail: rossielo@ terra.com.br 


\section{INTRODUÇÃO}

Dos nutrientes minerais essenciais para o crescimento vegetal, o nitrogênio $(\mathrm{N})$ é, quantitativamente, o mais importante (Engels e Marschner, 1995). A aquisição de $\mathrm{N}$ pelas plantas está regulada, de forma geral, por dois grupos de fatores: de um lado, estão aqueles ligados à disponibilidade das formas do $\mathrm{N}$ mineral na solução do solo, e do outro, os que regulam a demanda metabólica associada ao crescimento vegetal (Jeuffroy et al., 2002). Com relação aos fatores ligados ao vegetal, sabe-se que tanto a absorção quanto a assimilação do $\mathrm{N}$ exigem a aplicação de energia metabólica, o que liga sua utilização ao metabolismo de carbono (Lawlor, 2002).

A produção e o acúmulo de biomassa pela gramínea forrageira são resultantes das interrelações estabelecidas entre a assimilação fotossintética do carbono e a utilização dos fotoassimilados produzidos, nos sítios metabolicamente ativos (Robson et al., 1988). É justamente nesse nível que o $\mathrm{N}$ exerce os seus efeitos principais, posto que influencia tanto a atividade mitótica (produção celular) quanto a taxa de alongamento das novas células produzidas (Kavanová et al., 2008). Dessa forma, o $\mathrm{N}$ contribui para a expressão do tamanho final da folha, importante atributo estrutural do pasto e componente direto do índice de área foliar (IAF) (Chapman e Lemaire, 1993). Assim, como a absorção da radiação fotossinteticamente ativa (RFA) é dependente da área foliar disponível, parte dos benefícios do $\mathrm{N}$ sobre o crescimento das pastagens podem ser atribuídos aos efeitos diretos do nutriente sobre o IAF (Fernandes e Rossiello, 1995; Gastal e Lemaire, 2002).

Vários trabalhos têm ratificado, nos últimos anos, o papel central do IAF na modulação das respostas das plantas forrageiras aos vários estresses ambientais, ou diretamente ao pastejo animal, apontando a necessidade de se estudar e compreender melhor os aspectos relativos à estrutura do dossel em relação ao uso da radiação incidente (Da Silva e Nascimento Jr., 2007).

Para o caso de gramíneas estoloníferas, a capacidade de estabelecimento inicial deve guardar relação com a velocidade de alongamento dos estolões e da atividade meristemática localizada nas suas gemas, responsáveis pela emissão de novas raízes e colmos. Esses processos podem ser mais ou menos favorecidos em razão do nível nutricional do solo (Cruz e Boval, 2000). Em particular, cabe esperar que a existência de teores diferenciados de $\mathrm{N}$ no solo ocasione mudanças nas taxas de ocorrência dos diversos processos morfogenéticos e, por essa via, na estrutura dos dosséis (Chapman e Lemaire, 1993). Todavia, a magnitude das respostas das espécies forrageiras à disponibilidade de nutrientes dependerá das condições edafoclimáticas prevalescentes durante a estação de crescimento considerada. $\mathrm{O}$ presente trabalho teve como propósito quantificar os efeitos da adubação nitrogenada sobre o capim Tifton 85, em termos dos seguintes indicadores estruturais: ocorrência, altura do dossel, IAF e RFA, em experimento instalado no município de Seropédica, RJ.

\section{MATERIAL E MÉTODOS}

O trabalho foi realizado nas dependências da Estação para Pesquisas Parasitológicas "Wilhelm Otto Neitz" do Instituto de Veterinária da Universidade Federal Rural do Rio de Janeiro ( $22^{\circ} 45^{\prime} \mathrm{S}, 43^{\circ} 41^{\prime} \mathrm{W}$, altitude: 33 m.s.n.m), em área de ocorrência de planossolo háplico (Ramos et al., 1973). O clima da região enquadra-se no tipo Aw da classificação de Köppen, sendo caracterizado pela alternância de estação chuvosa no verão e seca no inverno, com precipitação anual da ordem de $1200 \mathrm{~mm}$ (Martorano et al., 1997). Uma análise da camada superficial (0 $0,2 \mathrm{~m}$ ) do solo revelou as seguintes propriedades químicas: $\mathrm{Ca}^{2+}=1,8 ; \mathrm{Mg}^{2+}=1,0 \mathrm{e} \mathrm{K}^{+}=$ $0,08 \mathrm{cmol}_{\mathrm{c}} / \mathrm{dm}^{3}$, respectivamente; M.O. = $17,0 \mathrm{~g} / \mathrm{kg} ; \mathrm{P}$ (Mehlich-1): $15,0 \mathrm{mg} / \mathrm{dm}^{3}$ e $\mathrm{pH}$ (água, 1:2,5) = 5,4. Em 11/09/2006, a área recebeu uma aplicação basal de $1000 \mathrm{~kg} / \mathrm{ha}$ de calcário dolomítico, em cobertura, seguida de gradagem para incorporação.

Cada parcela ou unidade experimental foi representada por um canteiro com $16 \mathrm{~m}^{2}$ de área total $(4 \times 4 \mathrm{~m})$. Os tratamentos, consistentes em doses de N-ureia $(0 ; 150 ; 300 ; 450$ e $600 \mathrm{~kg} / \mathrm{ha})$, com quatro repetições, foram dispostos segundo um delineamento em blocos inteiramente casualizados, com dose de $\mathrm{N}$ nas parcelas e dias de amostragem nas subparcelas, dentro de cada ciclo de rebrota, ou seja, dentro do período compreendido entre dois cortes consecutivos. Foram estudados quatro períodos de crescimento 
consecutivos, com duração de 43, 37, 36 e 42 dias.

O plantio foi realizado no dia 3/11/2006, utilizando-se estolões enraizados de capim, em sulcos espaçados de $1,0 \mathrm{~m}$ (cinco linhas e quatro entrelinhas). Nessa mesma data e antecedendo ao plantio, as parcelas receberam $150 \mathrm{~kg} \mathrm{P}_{2} \mathrm{O}_{5} / \mathrm{ha}$ (superfosfato simples), aplicado no fundo do sulco, misturado à terra, a uma profundidade de 0,1m. Em 24 de janeiro de 2007, foi feito um corte de uniformização, a uma altura de $0,1 \mathrm{~m}$, com auxílio de roçadeira costal. O N, na forma de ureia (solução aquosa) foi aplicado parceladamente. A primeira parcela foi aplicada aos 94 dias após plantio (DAP), e a metade restante aos 139 DAP, 12 dias após o primeiro corte experimental. Junto com as doses de $\mathrm{N}$, as parcelas receberam uma aplicação basal de cloreto de potássio, em solução aquosa, em dose equivalente a $600 \mathrm{~kg} / \mathrm{ha}$ de $\mathrm{K}$. Por meio de testes prévios, foi determinado o volume de água necessário para dissolver a quantidade de adubo a ser aplicada, na sua maior dosagem, sendo tal volume utilizado na aplicação de todos os tratamentos, visando promover, assim, uma distribuição uniforme dos nutrientes, dentro das parcelas.

Para a avaliação da frequência de ocorrência de plantas, foi adaptada uma variante do método de interseção (Ribeiro et al., 2007), conforme a seguinte expressão:

Frequência $=\frac{\mathrm{NP}_{\mathrm{i}}}{\mathrm{NTP}} \times 100$

em que $\mathrm{NP}_{i}$ é número de pontos intersectados e NTP é o número total de pontos passíveis de interseção. Para tal, foi confeccionado um quadrante de PVC, de 2 x $2 \mathrm{~m}$, dividido em quadrículas de $0,2 \times 0,2 \mathrm{~m}$, por meio de fiação de linha sintética, totalizando 81 pontos de interseção (= NTP, equação 1). A quadrícula era colocada sobre a superfície da parcela, registrando-se a presença ou ausência de algum elemento de vegetação, por meio do toque da lâmina foliar ou do colmo com o ponto de interseção. A altura do dossel foi medida com régua graduada em milímetros. Em cada ponto amostral, foram feitas duas medições, desde o nível do solo até o ponto mais alto e mais baixo de uma folha de acetato colocada sobre a superfície do relvado, obtendo-se, assim, um valor médio por parcela, a partir de quatro replicações.

O IAF foi determinado a partir do produto da massa seca de folhas verdes $\left(\mathrm{g} / \mathrm{m}^{2}\right)$ pela área foliar específica (AFE, $\mathrm{cm}^{2} / \mathrm{g}$ massa seca foliar). A massa seca foliar foi obtida a partir da massa verde contida dentro de um quadrante com $0,25 \mathrm{~m}^{2}$ de área interna, cortada a uma altura de $0,08 \mathrm{~m}$. O material foi levado à sombra, onde foi fracionado em lâminas foliares, colmos+bainhas e material senescente. Cada uma dessas frações foi posta a secar em estufa ventilada $\left(60 \pm 5^{\circ} \mathrm{C} ; 72\right.$ horas) até peso constante. A AFE foi determinada a partir da relação entre a área de discos foliares, obtidos com um furador de papel, e a massa seca desses discos. Para tal, em cada data de amostragem, foram coletados 10 discos foliares por parcela (área $=0,3002 \mathrm{~cm}^{2}$ ), que foram imediatamente imersos em água fria, para evitar perdas de matéria seca por desidratação. No laboratório, os discos foram enxugados ligeiramente com papel toalha e postos a secar, imediatamente, em estufa ventilada, a $65^{\circ} \mathrm{C}$, por 48 horas, sendo posteriormente pesados, em balança analítica com quatro casas decimais para obtenção da massa seca correspondente. As determinações do IAF foram feitas sempre ao final de cada um dos ciclos de rebrota.

As medições de radiação fotossinteticamente ativa (RFA, $\lambda=400-700 \mathrm{~nm}$ ) foram feitas sempre entre as 11:00 -12:00h, com céu claro, medindo-se a densidade de fluxo de fótons com auxílio de um sensor quântico modelo LI 190 SA (Licor, Nebraska, EUA) conectado a um medidor digital portátil modelo LI 250, (Licor, Nebraska, EUA). Em cada parcela, foi tomada uma leitura da RFA incidente $\left(\right.$ RFA $\left._{\text {inc }}\right)$ no topo do dossel, enquanto, no nível do solo, o valor da RFA representou a média de oito leituras consecutivas, tomadas em um período de 15 segundos. A RFA interceptada pelo relvado foi calculada como a diferença entre ambas as medições (incidente - transmitida até o solo) (Norman e Arkebauer, 1991), sendo expressa em termos de percentagem da RFA incidente, ou seja: 


$$
\operatorname{RFA}_{\text {Int }}(\%)=\frac{\left(\text { RFA }_{\text {incidente no topo }}-\mathrm{RFA}_{\text {transmitida até o solo }}\right)}{\text { RFA }_{\text {incidente no topo do dossel }}} \times 100
$$

Os dados meteorológicos relativos ao período experimental foram obtidos junto ao Posto da Estação Experimental de Seropédica, da PESAGRO-RJ, situado a uma distância de aproximadamente $1,5 \mathrm{~km}$. Os totais de chuva acumulada, dentro de cada ciclo de rebrota, foram de 241; 43; 113 e 48mm, valores que estão dentro dos limites de oscilação normal, de acordo com Martorano et al. (1997). As médias mensais das temperaturas máximas e mínimas do ar declinaram gradativamente do primeiro para o quarto ciclo de rebrota. Os valores médios máximos mais elevados ocorreram nos dois primeiros ciclos $\left(38,8\right.$ e $33,5^{\circ} \mathrm{C}$, respectivamente), e as mínimas mais baixas foram registradas nos dois últimos $(18,8 \mathrm{e}$ $17,1^{\circ} \mathrm{C}$, respectivamente).

Os dados primários relativos ao desenvolvimento temporal do dossel foram submetidos ao teste de normalidade de distribuição (KolmogorovSmirnov) e, subsequentemente, à análise de variância para identificar a significância dos efeitos de doses, dias de amostragens e da sua interação (teste $\mathrm{F}, \mathrm{P} \leq 0,05$ ). Em seguida, foram reanalisados utilizando-se o método funcional de análise de crescimento (Hunt, 1982). Para tal, foram utilizados os modelos de regressão não linear, disponíveis no manual do programa Graphpad Prism v.4.0 (Motulsky e Christopoulos, 2003). Os dados relativos à fração da RFA incidente interceptada foram ajustados a um modelo exponencial, utilizando-se IAF como variável independente (Russell et al.,1989).

\section{RESULTADOS E DISCUSSÃO}

A ocorrência foi um parâmetro utilizado como indicador indireto da velocidade de rebrota do dossel, em função dos dias após o corte. A análise estatística para cada um dos ciclos de rebrota indicou efeitos significativos para doses de $\mathrm{N}(\mathrm{P}<0,0001)$ e data de amostragem após o corte (DAC) $(\mathrm{P}<0,0001)$. A interação desses fatores resultou significativa $(\mathrm{P}<0,0001)$ somente no primeiro e segundo ciclos de rebrota. $\mathrm{Na}$
Fig. 1, são mostradas as funções de ajuste entre doses e DAC, para cada um dos cortes realizados. Para o primeiro ciclo de rebrota (Fig. 1A), a responsividade ao $\mathrm{N}$ expressou-se após 30 DAC, definindo três níveis: zero (tratamento testemunha); baixo (até $75 \mathrm{~kg} \mathrm{~N} /$ ha) e médio/alto (150-300kg N/ha). A máxima frequência observada, $(74 \%)$ correspondeu à dose de $225 \mathrm{~kg}$ $\mathrm{N} /$ ha, enquanto as mínimas corresponderam ao tratamento testemunha, que se estabilizaram em torno de $25 \%$, a partir de 22 DAC. No segundo ciclo (Fig. 1B), uma vez integralizadas as doses de $\mathrm{N}$, observou-se um padrão similar, porém com algumas variações interessantes. $\mathrm{Na}$ ausência de adubação nitrogenada, a frequência das plantas mostrou uma tendência de resposta quase linear sem, todavia, atingir valores superiores a $35 \%$. Por outro lado, os maiores níveis de aplicação atingiram valores máximos de frequência (80 a $91 \%$ ), superiores ao do primeiro ciclo. Durante o terceiro ciclo de rebrota (Fig. 1C), as respostas, ainda que pequenas, discriminaram entre os níveis baixo (150), médio (300) e alto (450/600kg N/ha), com freqüências máximas de 55, 61 e 70\%, respectivamente. Finalmente no quarto ciclo (Fig. 1D), o máximo valor observado $(40 \%)$ correspondeu à maior dose de aplicação, enquanto as freqüências correspondentes à menor dose igualaram-se às da testemunha. Tomados em conjunto, esses resultados indicam uma queda sazonal nos valores de frequência. Essa restrição na rebrota da pastagem é explicável pelas mudanças climáticas entre as estações de crescimento. Assim, nos meses de junho-julho, com dias mais curtos (redução de fotoperíodo), menor disponibilidade hídrica e temperaturas médias do ar em declínio (menor radiação líquida), as taxas de crescimento das plantas foram sendo progressivamente reduzidas. Um padrão de resposta similar, em relação ao vigor da rebrota de cinco cultivares de Cynodon, incluindo Tifton 85 , sob dose de $400 \mathrm{~kg} / \mathrm{ha}$ de $\mathrm{N}$ (ureia) em latossolo vermelho amarelo, foi observado previamente por Cecato et al. (2001). 

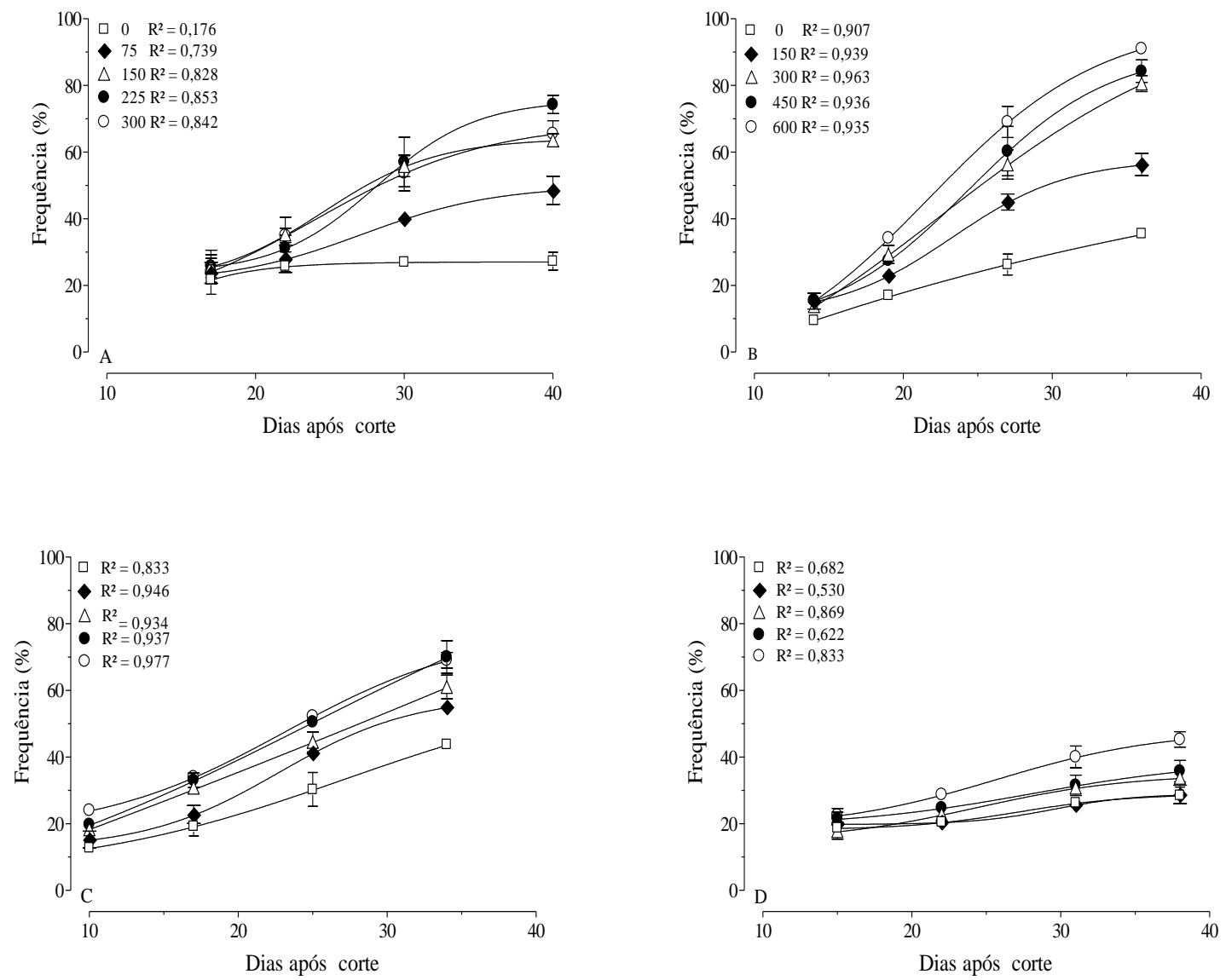

Figura 1. Frequência de ocorrência de plantas de Tifton 85 sob diferentes doses de N, em função dos dias após corte e ciclos sequenciais de rebrota. A: primeiro (25/01 - 10/03/2007); B: segundo (10/03 17/04/2007); C: terceiro (17/04 - 25/05/2007) e D: quarto (25/05 - 06/07/2007) ciclo, respectivamente.

A altura de plantas apresentou resposta significativa às doses de $\mathrm{N}(\mathrm{P}<0,0001)$ e aos dias de amostragens (DAC) $(\mathrm{P}<0,0001)$, e significância da interação N x DAC $(\mathrm{P}<0,0001)$, nos três primeiros ciclos de rebrota. De forma similar à frequência de ocorrência, a análise de regressão ajustou os dados a uma função tipo sigmoidal (Fig. 2A-D), confirmando observações prévias (Galzerano et al., 2008). No primeiro ciclo de rebrota, a altura do dossel definiu, a partir de 22 DAC, três grupos de resposta (sem $\mathrm{N}$, baixo $\mathrm{N}$ e médio-alto $\mathrm{N}$ ). No tratamentocontrole, a altura do dossel estabilizou-se em torno de $0,3 \mathrm{~m}$, aos $30 \mathrm{DAC}$, enquanto, nos níveis médio-alto, a altura média foi de $0,54 \mathrm{~m}$ (Fig. 2A). No segundo ciclo, a altura do dossel oscilou entre um mínimo de $0,22 \mathrm{~m}$ e um máximo de 0,46m, para os níveis de zero e $600 \mathrm{~kg} \mathrm{~N} / \mathrm{ha}$, respectivamente (Fig. 2B). O terceiro ciclo (Fig. 2C) apresentou um padrão de resposta semelhante ao anterior, com altura máxima de $0,44 \mathrm{~m}$ (600kg N/ha) e mínima de $0,22 \mathrm{~m}$ no nível zero de N. Finalmente, no quarto ciclo (Fig. 2D), houve queda acentuada na altura do dossel, devido às variações climáticas já comentadas. 

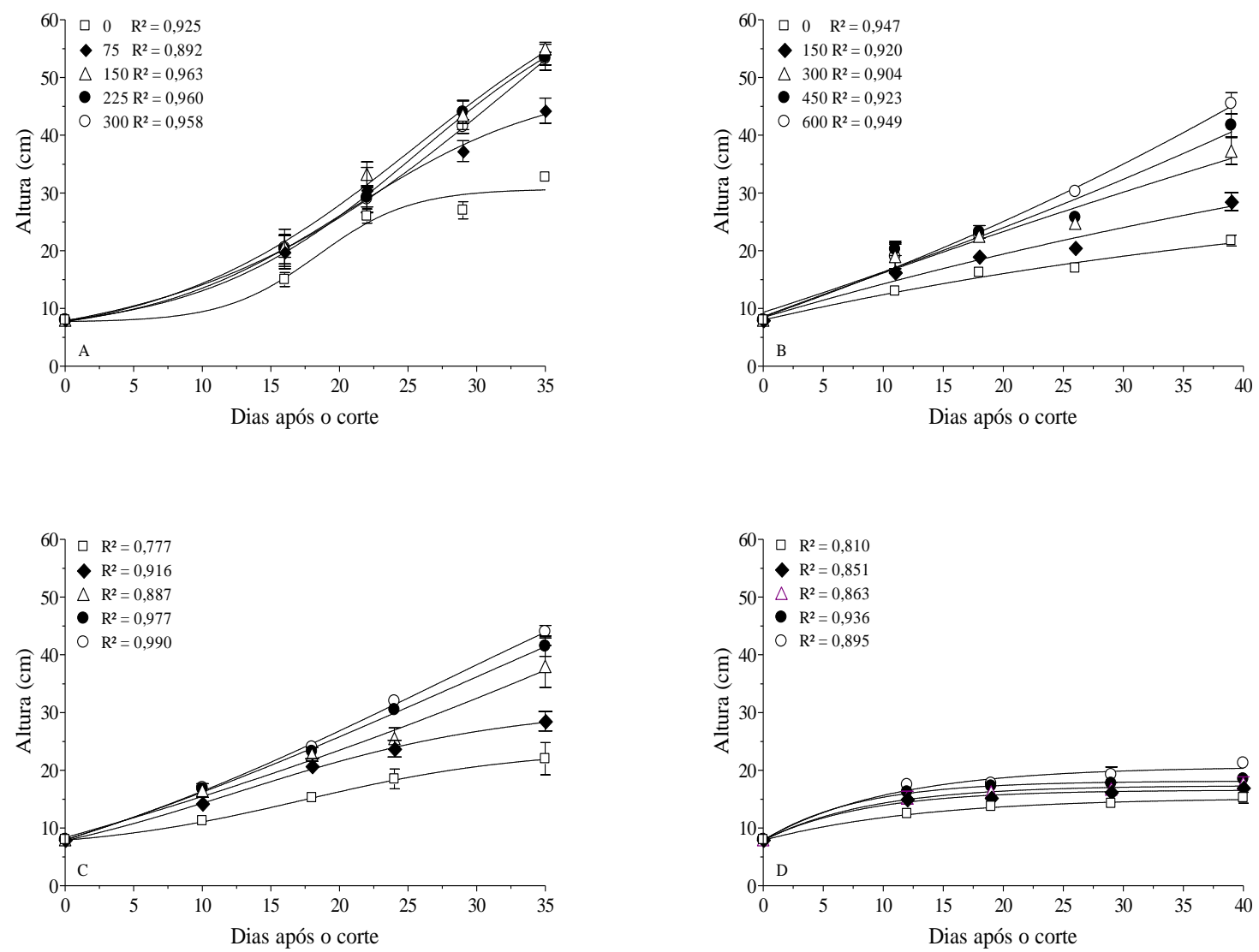

Figura 2. Altura do dossel de Tifton 85 sob diferentes doses de N, em função dos dias após corte e ciclos sequenciais de rebrota. A: primeiro (25/01 - 10/03/2007); B: segundo (10/03 - 17/04/2007); C: terceiro (17/4 - 25/05/2007) e D: quarto (25/5 - 06/07/2007) ciclo, respectivamente.

A análise estatística dos valores de IAF indicou haver efeitos significativos tanto para doses de $\mathrm{N}$ quanto para cortes $(\mathrm{P}<0,0001)$, assim como para a sua interação $(\mathrm{P}=0,0034)$. A Fig. 3 mostra a distribuição dos valores de IAF em função dos níveis de $\mathrm{N}$ em cada um dos cortes realizados. Os valores variaram de 0,78 a 4,19 por ocasião do primeiro corte, de 0,80 a 3,44 no segundo, de 1,21 a 2,91 no terceiro e de 0,76 a 1,60 no quarto. Com exceção do primeiro ciclo, em que a produção de área foliar atingiu seu máximo antes da maior dose de $\mathrm{N}$, em cada ciclo subsequente verificou-se que a produção de área foliar foi sempre crescente, em função da disponibilidade de N. Isto está de acordo com os efeitos geralmente reconhecidos do $\mathrm{N}$ sobre o crescimento foliar (Cruz e Boval, 2000). As reduções nos valores de IAF, nos terceiro e quarto cortes (Fig. 3), podem ser atribuídas às variações sazonais das condições climáticas, já mencionadas.

A análise dos valores de $\mathrm{RFA}_{\text {int }}$ indicou haver efeitos significativos tanto para doses de $\mathrm{N}$ quanto para DAC $(\mathrm{P}<0,0001)$, nos quatro ciclos de rebrota estudados, observando-se efeitos de interação no primeiro $(\mathrm{P}<0,0019)$ e no segundo $(\mathrm{P}<0,0011)$ ciclo de rebrota. No primeiro ciclo (Fig. 4A), a resposta do dossel ocorreu em dois níveis: sem $(-\mathrm{N})$ e com nitrogênio $(+\mathrm{N})$. Em todos os tratamentos $+\mathrm{N}$, o dossel atingiu uma interceptação de $95 \%$ da RFA incidente (Parsons et al., 1983), entretanto houve diferenças quanto aos dias necessários para atingir tal condição. Nas três maiores doses, os respectivos dosséis alcançaram $95 \%$ de interceptação aos 29 DAC, enquanto aos 36 DAC a interceptação do tratamento $-\mathrm{N}$ não excedeu $76 \%$. Esses dados evidenciam claramente o efeito promotor do $\mathrm{N}$ sobre as taxas de crescimento de folhas e perfilhos, órgãos responsáveis pela interceptação. No segundo e no terceiro ciclo, somente nas duas maiores doses registraram-se níveis de interceptação de $95 \%$ da radiação incidente, aos 39 e 35 DAC, respectivamente (Fig. 4B e C). Esses resultados indicam que, com a redução progressiva da velocidade de crescimento das plantas, o dossel necessita de maior número de dias para atingir o nível de interceptação crítico de $95 \%$, após o qual o 
acúmulo de colmos e a senescência são drasticamente intensificados (Da Silva e Nascimento Jr., 2007). Já no último ciclo, durante o mês de junho, o nível máximo de interceptação, no maior nível de $\mathrm{N}$ aplicado, não excedeu $82 \%$ (Fig. 4D), evidenciando a limitação dos fatores de crescimento sobre a captura da luz incidente pelo do dossel e, portanto, sobre o acúmulo de matéria seca. Essa resposta à maior dose de $\mathrm{N}$ encontrada no quarto ciclo de rebrota foi comum para todas as variáveis estudadas, evidenciando, assim, um efeito residual de $\mathrm{N}$ aplicado.

Alvim et al. (1999) observaram que, sem irrigação, o potencial de produção de matéria seca do Tifton 85 na época da seca, na região Sudeste do país, é limitado. Esses autores também observaram que, na ausência de adubação nitrogenada, essa forrageira tem pouca habilidade para competir com plantas invasoras, e, portanto, para melhorar a sua persistência em áreas de várzea, além da aplicação de doses elevadas de $\mathrm{N}$, é preciso que o corte seja menos intenso e realizado a intervalos mais amplos. Essas observações ajustam-se adequadamente ao presente experimento, em que ficou bem documentada a progressiva redução do tamanho do dossel, nos sucessivos cortes, em função das restrições ambientais ao crescimento do capim. Nesse sentido, os dados de frequência de ocorrência (Fig. 1) são bastante expressivos e mostram, incidentalmente, que a metodologia utilizada para a sua avaliação, simples e não destrutiva, pode constituir um indicador apropriado da persistência do Tifton 85 .

Na Fig. 5, mostra-se a relação obtida quando o IAF foi relacionado quantitativamente à interceptação de RFA. A natureza assintótica da curva é típica e tem sido demonstrada principalmente para gramíneas de clima temperado (Hodgson, 1990; Viegas et al., 1999). Para o presente estudo, e considerando-se os valores conjuntos dos quatro ciclos de rebrota, a função de ajuste indicou que a fração interceptada da RFA incidente atingiu 95\%, com valores de IAF de 3,9-4,0. De uma forma geral, Humphreys (1966) observou, para pastagens, que os valores de $\mathrm{RFA}_{\text {int }}=95 \%$ estavam associados a valores de IAF na faixa de 3 a 5 . Fagundes et al. (2001), ao trabalharem com cultivares de Cynodon spp., submetidas ao pastejo de ovinos, em regime de lotação contínua, obtiveram, para o Tifton 85 , mantido a uma altura média de $0,2 \mathrm{~m}$, valores de interceptação luminosa entre 93 e $98 \%$ entre os meses de julho e dezembro. O presente estudo foi realizado sob regime de cortes e em condições edafoclimáticas bem diferenciadas em relação ao estudo citado. Todavia, ficou evidente que, de forma similar ao observado por Fagundes et al. (2001), pastos de Tifton 85 com maior altura do dossel apresentaram maiores valores de IAF e de interceptação da RFA incidente.

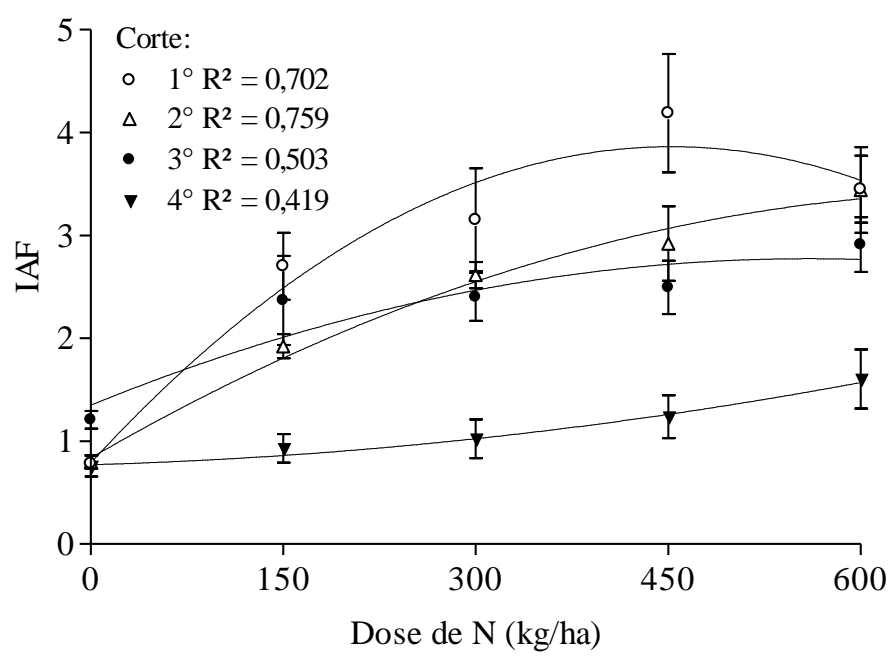

Figura 3. Índices de área foliar (IAF) obtidos ao final de quatro ciclos de rebrota em parcelas experimentais do capim-Tifton 85 sob diferentes doses de N. Cortes das parcelas realizados em: 25/01; 10/03; 17/04; 25/05 e 06/07/2007. 

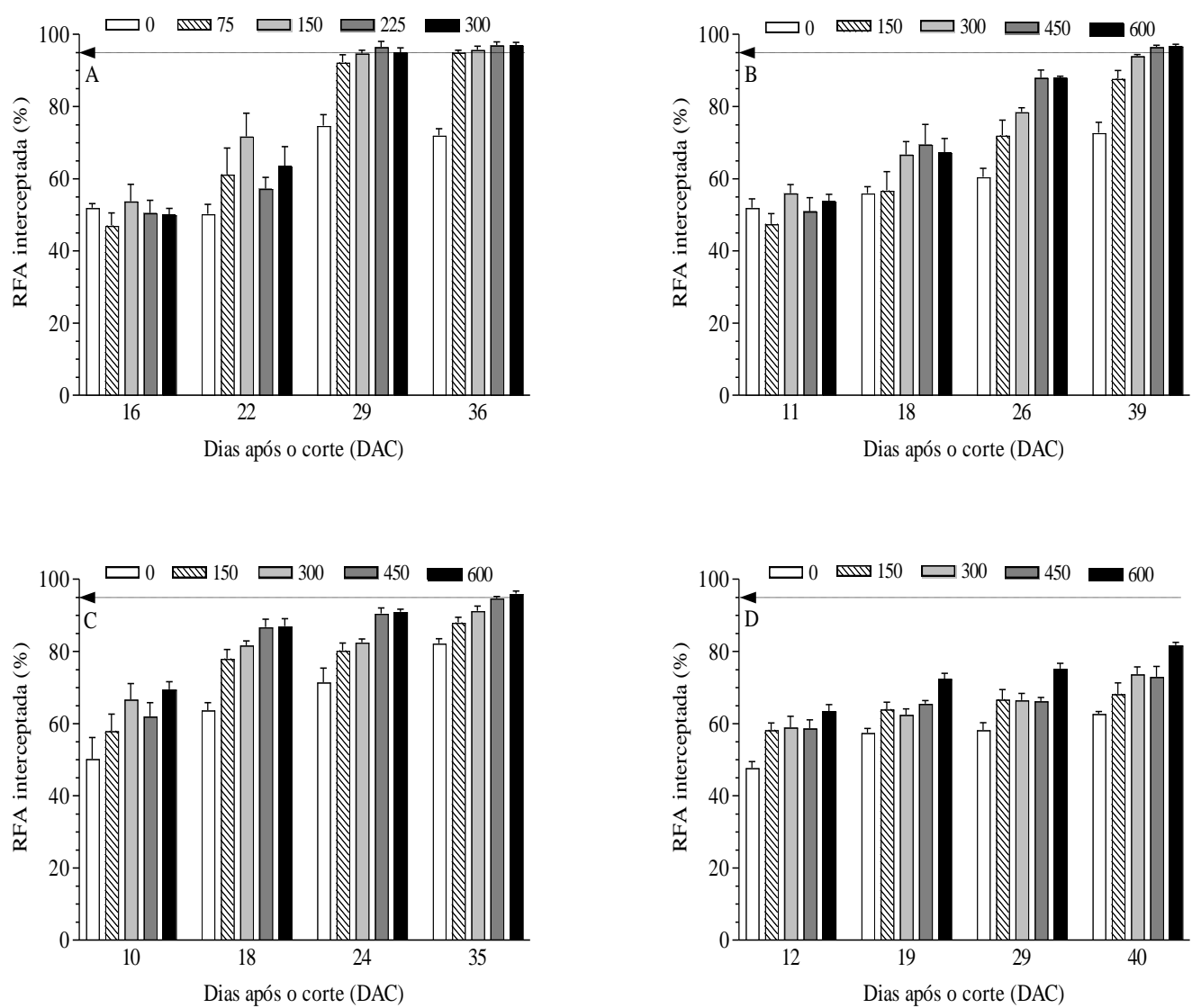

Figura 4. Radiação fotossinteticamente ativa interceptada pelo dossel de Tifton 85, sob diferentes doses de N, em função dos dias após corte e ciclos sequenciais de rebrota. A: primeiro (25/01 - 10/03/2007); B: segundo (10/03 - 17/04/2007); C: terceiro (17/04 - 25/05/2007) e D: quarto (25/05 - 06/07/2007) ciclo, respectivamente. A seta indica o valor de RFA interceptada $=95 \%$.

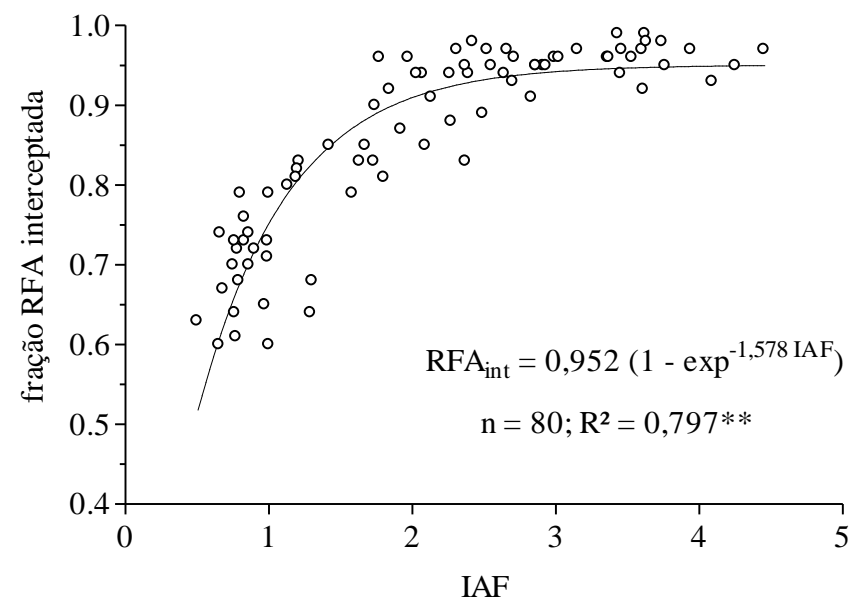

Figura 5. Relação entre a fração da irradiância fotossinteticamente ativa interceptada e o índice de área foliar (IAF), obtida em parcelas experimentais do capim-Tifton 85. Cada ponto corresponde a uma observação por parcela, para cinco doses de $\mathrm{N}$ e quatro ciclos de rebrota. Amostragens realizadas no período fevereiro - julho de 2007. 


\section{CONCLUSÕES}

Tanto a ocorrência de plantas como a altura do dossel responderam à adubação nitrogenada, conforme um padrão de resposta que variou sazonalmente, em função das doses de $\mathrm{N}$ aplicadas em interação com as condições ambientais, evidenciando, assim, a sua sensibilidade como indicadores de crescimento do dossel forrageiro do capim-Tifton 85. A expansão da área foliar e a interceptação da radiação fotossinteticamente ativa associada, também foi controlada direta e proporcionalmente pelas doses de $\mathrm{N}$ aplicadas, sendo maximizada a valores de índice de área foliar em torno de 4,0.

\section{REFERÊNCIAS BIBLIOGRÁFICAS}

ALVIM, M.J.; XAVIER, D.F.; VERNEQUE, R.S. et al. Resposta do Tifton 85 a doses de nitrogênio e intervalos de cortes. Pesq. Agropec. Bras., v.34, p.2345-2352, 1999.

CECATO, U.; SANTOS, G.T.; MACHADO, M.A. et al. Avaliação de cultivares do gênero Cynodon com e sem nitrogênio. Acta Scient., v.23, p.781-788, 2001.

CHAPMAN, D.F.; LEMAIRE, G. Morphogenetic and structural determinants of plant regrowth after defoliation. In: BAKER, M.J. (Ed). Grassands for our world. Wellington: Sir Publishing, 1993. p.55-64.

CRUZ, P.; BOVAL, M. Effect of nitrogen on some morphogenetic traits of temperate and tropical perennial forage grasses. In: LEMAIRE, G.; HODGSON, J.; MORAES, A. et al. (Eds). Grassland ecophysiology and grazing Ecology. New York: CABI Publishing, 2000. p.151-168.

DA SILVA, S.C.; NASCIMENTO Jr., D. Avanços na pesquisa com plantas forrageiras tropicais em pastagens: características morfofisiológicas e manejo do pastejo. Rev. Bras. Zootec., v.36, supl. especial, p.121-138, 2007.

ENGELS, C.; MARSCHNER, H. Plant uptake and utilization of nitrogen. In: BACON, P.E. (Ed). Nitrogen fertilization in the enviroment. New York: Marcel Dekker, Inc., 1995. p.41-81.
FAGUNDES, J.L.; DA SILVA, S.C.; PEDREIRA, C.G.S. et al. Índice de área foliar, coeficiente de extinção luminosa e acúmulo de forragem em pastagens de Cynodon spp. sob lotação contínua. Pesq. Agrop. Bras., v.36, p.187-195, 2001.

FERNANDES, M. S.; ROSSIELLO, R. O. P. Mineral nitrogen in plant physiology and plant nutrition. Crit. Rev. Plant Sci., v.14, p.111-148, 1995.

GASTAL, F.; LEMAIRE, G. $\mathrm{N}$ uptake and distribution in crops: an agronomical and ecophysiological perspective. J. Exp. Bot., v.53, p.789-799, 2002.

GALZERANO, L.; ROSSIELLO, R.O.P.; OLIVEIRA, A.P.P. et al. Mudanças em atributos estruturais de dosséis do capim-Tifton 85, na fase de estabelecimento, induzidas pela adubação nitrogenada. Bol. Industr. Anim., v.65, p.329336, 2008.

HODGSON, J. Grazing management: science into practice. Essex: Longman Scientific and Technical, 1990. 203p.

HUMPHREYS, L.R. Subtropical grass growth. II. Effects of variation in leaf area index in the field. Qld. J. Agric. Anim. Sci., v.23, p.337-358, 1966.

HUNT, R. Plant growth curves. London: Edward Arnold Ltd., 1982. 248p.

JEUFFROY, M.H.; NEY, B.; OURRY, A. Integrated physiological and agronomic modelling of $\mathrm{N}$ capture and use within the plant. J. Exp. Bot., v.53, p.809-823, 2002.

KAVANOVÁ, M.; LATTANZI, F.A.; SCHNYDER, H. Nitrogen deficiency inhibits leaf blade growth in Lolium perenne by increasing cell cycle duration and decreasing mitotic and post-mitotic growth rates. Plant Cell Environ., v.31, p.727-737, 2008.

LAWLOR, D.W. Carbon and nitrogen assimilation in relation to yield: mechanisms are the key to understanding production systems. $J$. Exp. Bot., v.53, p.773-787, 2002.

MARTORANO, L.G.; MATOS, R.M.B.; SILVA, E.M.R. et al. Disponibilidade climática para cultivo da bananeira na região de Seropédica, Itaguaí-RJ. In: CONGRESSO BRASILEIRO DE AGROMETEOROLOGIA, 10., 1997. Piracicaba. Anais... SBA, 1997. p.301-303. 
MOTULSKY, H.J.; CHRISTOPOULOS, $A$. Fitting models to biological data using linear and nonlinear regression. A practical guide to curve fitting. San Diego: Graph Pad Software. Inc., 2003. 351p.

NORMAN, J.M.; ARKEBAUER, T.J. Predicting canopy light-use efficiency from leaf characteristics. In: HANKS, J., RITCHIE, J.T. Modeling plant and soil systems. Madison: American Society of Agronomy, 1991. p.125144.

PARSONS, A.J.; LEAFE, E.L.; COLLET, B. et al. The physiology of grass production under grazing. I. Characteristics of leaves and canopy photosynthesis of continuously grazed swards. $J$. Appl. Ecol., v.20, p.117-126, 1983.

RAMOS, D.P.; CASTRO, A.F.; CAMARGO, M.N. Levantamento detalhado de solos da área da Universidade Federal Rural do Rio de Janeiro. Pesq. Agropec. Bras. Ser. Agron., v.8, p.1-27, 1973.

RIBEIRO, R.C.; ROSSIELLO, R.O.P.; MACEDO, R.O. et al. Introdução de desmódio em pastagem estabelecida de Brachiaria humidicola: densidade e frequência da leguminosa no consórcio. Rev. Univ. Rural Ser. Cienc. Vida, v.27, p.41-49, 2007.
ROBSON, M.J.; RYLE, G.J.A.; WOLEDGE, J. The grass plant - its form and function. In: JONES, M. B.; LAZENBY, A. (Eds). The grass crop: the physiological basis of production. London: Chapman and Hall, 1988. cap.2, p.2583.

RUSSEL, G.; JARVIS, P.G.; MONTEITH, J.L. Absorption of radiation by canopies and stand growth. In: RUSSELL, G.; MARSHALL, B.; JARVIS, P.G. (Eds). Plant canopies: their growth, form and function. Cambridge: Cambridge University, 1989. p.21-39.

VIEGAS, J.; NABINGER, C.; MEDEIROS, R.B. et al. Forage accumulation of annual ryegrass as function of solar radiation absorption In: SIMPÓSIO INTERNACIONAL "GRASSLAND ECOPHYSIOLOGY AND GRAZING ECOLOGY", 1., 1999, Curitiba. Anais... Curitiba: UFPR/UFRGS, 1999. p.387- 391.(Resumo). 